\title{
Wind observations above an urban river using a new lidar technique, scintillometry and anemometry
}

Article

Accepted Version

Wood, C. R., Pauscher, L., Ward, H. C., Kotthaus, S., Barlow, J., Gouvea, M., Lane, S. E. and Grimmond, C. S. B. (2013) Wind observations above an urban river using a new lidar technique, scintillometry and anemometry. Science of the Total Environment, 442. pp. 527-533. ISSN 0048-9697 doi:

https://doi.org/10.1016/j.scitotenv.2012.10.061 Available at https://centaur.reading.ac.uk/28978/

It is advisable to refer to the publisher's version if you intend to cite from the work. See Guidance on citing.

To link to this article DOI: http://dx.doi.org/10.1016/j.scitotenv.2012.10.061

Publisher: Elsevier

All outputs in CentAUR are protected by Intellectual Property Rights law, including copyright law. Copyright and IPR is retained by the creators or other copyright holders. Terms and conditions for use of this material are defined in the End User Agreement. 


\section{CentAUR}

Central Archive at the University of Reading

Reading's research outputs online 
Wood CR, Pauscher L, Ward HC, Kotthaus S, Barlow JF, Gouvea M, Lane SE, Grimmond CSB (2012)

Wind observations above an urban river using a new lidar technique, scintillometry and

anemometry. Science of the Total Environment DOI:10.1016/j.scitotenv.2012.10.061

Department of Meteorology, University of Reading, Reading, RG6 6BB, United Kingdom

Finnish Meteorological Institute, Erik Palménin aukio 1, Helsinki, 00101, Finland

King's College London, Department of Geography, London, WC2R 2LS, United Kingdom

Centre for Ecology and Hydrology, Wallingford, Oxfordshire, OX10 8BB, United Kingdom

Corresponding author: Dr Curtis R. Wood, Curtis.Wood-ÅT-fmi.fi

\section{Keywords}

Scanning Doppler lidar; roughness sub-layer; instrument comparison; urban climate; micrometeorology; sonic anemometry

\section{Highlights}

- An inter-comparison was made between lidar-derived winds and regular anemometry.

- A new lidar operating technique was developed.

- Airflow features above an urban river included channelling of wind.

\section{Abbreviations footnote}

BLS (Boundary-layer scintillometer), CSAT3 (a sonic anemometer model), KCL (King's College London), KSK (KCL Strand campus King's building), KSS (KCL Strand campus Strand building), KWJ (KCL Waterloo campus James Clark Maxwell building).

\section{ABSTRACT}

Airflow along rivers might provide a key mechanism for ventilation in cities: important for air quality and thermal comfort. Airflow varies in space and time in the vicinity of rivers. Consequently, there is limited utility in point measurements. Ground-based remote sensing offers the opportunity to study 3D airflow in locations which are difficult to observe with conventional approaches. For three months in the winter and spring of 2011, the airflow above the River Thames in central London was observed using a scanning Doppler lidar, a scintillometer and sonic anemometers. First, an intercomparison showed that lidar-derived mean wind-speed estimates compare almost as well to sonic anemometers (root-mean-square error (rmse) $0.65-0.68 \mathrm{~m} \mathrm{~s}^{-1}$ ) as comparisons between sonic anemometers $\left(0.35-0.73 \mathrm{~m} \mathrm{~s}^{-1}\right)$. Second, the lidar duo-beam operating strategy provided horizontal transects of wind vectors (comparison with scintillometer rmse 1.12-1.63 $\mathrm{m} \mathrm{s}^{-1}$ ) which revealed mean and turbulent airflow across the river and surrounds; in particular, channelled airflow along the river and changes in turbulence quantities consistent with the roughness changes between built 
and river environments. The results have important consequences for air quality and dispersion around urban rivers, especially given that many cities have high traffic rates on roads located on riverbanks.

\section{Introduction}

Urban air quality depends on ventilation processes. Whilst the atmospheric boundary-layer depth determines air-pollutant concentrations (Chou et al., 2007), it is important to understand all processes that drive urban ventilation and thus air quality. Studies from point-location instruments on buildings are numerous, but there are some city forms (rivers, parks) that are difficult to study with point measurements alone; and point measurements might be biased because of siting limitations. The use of ground-based remote sensing can thus help to give a more representative analysis of airflow.

In the atmosphere above cities, airflow depends on the morphology of the urban surface (Barlow and Coceal, 2009). More-studied urban components include buildings (Vardoulakis et al., 2011; Yuan and Ng, 2012), street canyons (Eliasson et al., 2006; Kastner-Klein et al., 2001; Salizzoni et al., 2009), and intersections (Balogun et al., 2010). The airflow over larger-scale urban features, such as rivers or parks also needs to be understood (Spronken-Smith et al., 2000). Rivers might provide a key mechanism for ventilation in cities (Cho, 2010) analogous to street canyons - such as in model studies (Ding et al., 2004). However, latent and sensible heat fluxes above rivers (Ching, 1985) have received comparatively little attention. Some mesoscale processes also affect ventilation: for example in coastal cities, the interactions between tidal and sea-breeze variation (e.g. estuary turbulence, Ding et al., 2004) and sea-breeze propagation (e.g. over $70 \mathrm{~km}$ inland along the Hudson river, Orton et al., 2010). However, urban airflows need to be better understood in order to become explicitly parameterized in numerical weather prediction (NWP) models. With the increase in NWP models' spatial resolution (Best, 2005) urban features, such as rivers, are of increasing importance. However, these are often hard to study with traditional point measurements, but ground-based remote sensing (such as scintillometers or lidars) can overcome this.

Scanning Doppler lidars permit spatially-resolved analysis of airflow, especially when augmented with high-quality point measurements such as eddy-covariance stations, and are being deployed for urban boundary layer studies (Barlow et al., 2011). Dual-beam scintillometers are capable of estimating the mean wind speed component perpendicular to the beam, in addition to their more common use in obtaining area-averaged sensible heat fluxes. To our knowledge, there are currently no published reports of wind speed analyses in cities using scintillometers. Different methods are used to obtain wind speed from scintillometry and have been evaluated in simpler environments (van Dinther et al., 2012; Ting-i Wang et al., 1981) and over complex terrain in the 
Wood et al. (2012) Science of the Total Environment DOI:10.1016/j.scitotenv.2012.10.061

Alps (Poggio et al., 2000). Scintillometers are increasingly being used in urban areas for sensible heat flux estimates, including: Tokyo (Kanda et al., 2002), Basel (Roth et al., 2006), Marseilles (Lagouarde et al., 2006), Łódź (Fortuniak and Pawlak, 2011), Nantes (Mestayer et al., 2011), Helsinki (Wood et al., 2012) and London.

In the present paper, observations of wind velocity and turbulence across a river in a dense urban area are presented. A duo-beam method, using a scanning Doppler lidar, to determine horizontally-resolved paths of wind vectors is described. This is tested against both point wind measurements and path-averaged measurements from a scintillometer. Then, the lidar data are used to explore the spatial and temporal characteristics of the airflow above the river.

\section{Methods}

\subsection{Study period and study area}

This study was undertaken in the winter and spring of 2011 (18-February to 17-May; day of year 49-137), in central London UK (Fig. 1). The location was across the River Thames, at about 30$50 \mathrm{~km}$ west of the North Sea, where the mean river-flow is towards the east. The river height varies 3.8-6.7 $\mathrm{m}$ at London Bridge (Port of London, 2011), approximately $2 \mathrm{~km}$ downstream of the study site.

Morphology characteristics are calculated as background information for the study area (Fig. 1) with respect to the centre point of the boundary-layer scintillometer (BLS) beam over the River Thames for a $1 \mathrm{~km}$ radius. A digital elevation model (Evans, 2009; Lindberg and Grimmond, 2011), without vegetation, is used to determine mean building height, zero-plane displacement height (MacDonald et al., 1998) and roughness length for momentum (MacDonald et al., 1998); these are $18.9,10.5$ and $1.6 \mathrm{~m}$, respectively, with a plan area index of 0.31 and a frontal area index of 0.28 . The aspect ratio of the 'river canyon' (ratio of bankside building height to river width) is approximately 0.1 (i.e. Fig. 1 ).

\subsection{Mast-borne measurements}

Point measurements near the river were taken on two masts at King's College London (KCL), Strand Campus $\left(51.50^{\circ} \mathrm{N}, 0.12^{\circ} \mathrm{W}\right)$ : referred to as KSS and KSK. At both sites, CSAT3 sonic anemometers, of accuracy $0.04 \mathrm{~m} \mathrm{~s}^{-1}$ (Campbell Scientific Inc, Logan, USA), were located on top of measurement masts to sample the 3D-wind vector at $10 \mathrm{~Hz}$. 2D-wind measurements were available from an automatic weather station WXT510 of accuracy $\pm 0.3 \mathrm{~m} \mathrm{~s}^{-1}$ or $\pm 2 \%$ whichever is greater (Vaisala Oy, Vantaa, Finland). This WXT was located at KSS, sampling at $0.2 \mathrm{~Hz}$ and this WXT dataset was scalar averaged up to 1-min, before being vector averaged to 30-min. Data processing is as described in Kotthaus and Grimmond (2012). Sensor heights are $49 \mathrm{~m}$ a.g.l. (2.3 times the mean 
building height $\left.z_{H}\right)$ and $39 \mathrm{~m}$ a.g.I. $\left(1.8 z_{\mathrm{H}}\right)$ at KSS and KSK, respectively (Kotthaus and Grimmond, 2012).

\subsection{Scintillometer}

A Boundary Layer Scintillometer BLS900 (BLS, Scintec AG, Rottenburg, Germany) was installed with an $808 \mathrm{~m}$ near-horizontal path transmitted from the roof of the $\mathrm{KCL}$ James Clark Maxwell building on the Waterloo campus (KWJ, to the south-east of the Strand KCL site) building and received on the roof of the KSS building. BLS data comprise spatially integrated values of structure parameter of refractive-index fluctuations $C_{n}^{2}$ and cross-beam wind component (a standard output from Scintec's SRun software which is based on the time lagged cross-covariance function of the two beams; see e.g. (van Dinther et al., 2012; Ward et al., 2011)). Here, wind speeds are given as positive when the wind is blowing from $157.8-337.8^{\circ}$, and negative for $337.8-157.8^{\circ}$.

The path weighting of the BLS is bell shaped (Scintec, 2011; Ward et al., 2011), and the centre of the path accounts for most of the signal. Hence, the river portion of the path $(300 \mathrm{~m})$ comprises $69 \%$ of the total weighting. The beam is approximately $40-50 \mathrm{~m}$ above mean river level (Fig. 1b).

A known chimney, a strong anthropogenic source of heat and moisture, was located immediately to the north-east of the BLS transmitter (KWJ) and affected observations under easterly airflow conditions. The primary BLS dataset excludes measurement periods with wind directions from $10-120^{\circ}$ (defined using KSS CSAT3 anemometer) because of suspected heat/moisture contamination, so the frequency of negative BLS winds speeds were reduced. This BLS dataset was sub-sampled to include only positive BLS wind, to remove any possible contamination and in order not to introduce bias due to sub-sampling of wind directions - thus creating a very-high-quality dataset.

Data were quality controlled for rain events and low atmospheric transmissivity (e.g. fog). Periods during which the BLS had low signal levels, or the rain-gauge (ARG100, Campbell Scientific) located next to the KSK mast recorded rain, were rejected at 1-min intervals.

\subsection{Lidar}

The scanning Doppler lidar used was a Streamline (HALO Photonics, Malvern, UK) operating at $1.5 \mu \mathrm{m}$ wavelength, the same model as used previously to study boundary-layer structure in London (Barlow et al., 2011). The lidar was located at the same height (on the KSS rooftop) as the BLS receiver, and within $10 \mathrm{~m}$ horizontally (i.e., the lidar was $45 \mathrm{~m}$ west of the KSS mast). Data were recorded at $30 \mathrm{~m}$ resolution (range-gates). A blind-region, where no data were available, existed in the first three range-gates (i.e. $0-90 \mathrm{~m}$ ). The lidar rays pointed horizontally (i.e. $0^{\circ}$ elevation) and so 
although 27 usable lidar range-gates should exist along the path of the BLS beam, only range-gates 4 to 18 were available for comparison due to the lidar blind region and spurious lidar returns from buildings beyond range-gate 18 . Since the lidar cannot operate below $0^{\circ}$ elevation, lidar horizontal rays were slightly higher than the BLS beam (Fig. 1b). Given the BLS's slanted beam and the blind region of the lidar, the lidar's sampling regions are 1.1-6.6 $\mathrm{m}$ above that of the scintillometer at range-gates $4-18$ respectively (Fig. 1 b).

A 1-second integration was made every $3.5 \mathrm{~s}$, thus $3.5 \mathrm{~s}$ is the minimum time interval between concurrent rays. An established quality-control method was performed on the lidar velocity data (of resolution $0.023 \mathrm{~m} \mathrm{~s}^{-1}$ ) using a fixed threshold of $\sigma_{\mathrm{e}}=0.1 \mathrm{~m} \mathrm{~s}^{-1}$, where $\sigma_{\mathrm{e}}$ is a standard deviation representing measurement error (O'Connor et al., 2010), and is based on a signal-to-noise ratio (SNR) threshold corresponding to a limit of SNR of about $-20 \mathrm{~dB}$ (Barlow et al., 2011).

\subsubsection{Duo-beam method}

For most of the lidar schedule, standard operating strategies were performed for other work, such as vertical stares and vertical profiles of horizontal wind vectors. In addition to those, for this study, custom operating strategies were added to the schedule: horizontal stares at particular azimuth angles of $A=180.0^{\circ}$ and $B=157.8^{\circ}$ (bearings from North, see Fig. 1a). The pair of rays was scheduled six times per 300 s period (which used 14\% of lidar's operating time). Thus 36 azimuth pairs of horizontal rays (which we term samples, N) were used to define mean wind in each period (30-min-mean winds were used for analysis to obtain statistically-large-enough samples to permit analysis, see sections 3 and 4).

To convert radial Doppler velocity along each ray to a resolved path of wind vectors across the river, the following trigonometric relations and assumptions are applied. Before trigonometric manipulation, the data in each ray at each range-gate were first averaged to 30-min-mean values. The radial velocity can be expressed as $\nu_{\mathrm{r}}^{\mathrm{g}}$; where $g$ is the range-gate number, and $r$ is the ray (A or B). The measurement can be defined in terms of the transect of wind speed $\left(U^{\mathrm{g}}\right)$ and direction $\left(\phi^{\mathrm{g}}\right.$, bearing from grid-North):

$$
\nu_{\mathrm{r}}^{\mathrm{g}}=U^{\mathrm{g}} \cos \left(\phi^{\mathrm{g}}+\pi-\theta_{\mathrm{r}}\right),
$$

where $\theta_{\mathrm{r}}$ is the bearing of the ray ( $\mathrm{A}$ or $\mathrm{B}$ ). The wind vector at each distance (range-gate) along the path can be calculated from the information from the two rays: i.e. there are two simultaneous equations each with two knowns and two unknowns. This can be conducted along the pair of rays ( $A$ B) to give an estimate of the path of wind vectors across the river. Re-arrangement of standard trigonometric identities yields:

$$
\phi^{\mathrm{g}}=\tan ^{-1}\left(\frac{v_{\mathrm{A}}^{\mathrm{g}} \cos \theta_{\mathrm{B}}-v_{\mathrm{B}}^{\mathrm{g}} \cos \theta_{\mathrm{A}}}{v_{\mathrm{B}}^{\mathrm{g}} \sin \theta_{\mathrm{A}}-v_{\mathrm{A}}^{\mathrm{g}} \sin \theta_{\mathrm{B}}}\right) .
$$


The solution is given for $-\pi$ to $+\pi$. The resulting sign ambiguity was resolved using the sign of beam A. Once $\phi^{\mathrm{g}}$ is known, $U^{\mathrm{g}}$ is found by re-arranging (1).

In this trigonometric calculation, there is an implicit assumption that the measurements at each range-gate distance are at the same point, as is commonly assumed in many scanning strategies such as the commonly-used vertical-azimuth display (VAD). However, beams A and B clearly diverge from each other by distances of 36-218 m over range-gates 4-18 (Fig. 1a) and thus the samples in each of beams A and B will have sampled different locations. This inevitably will cause some scatter in analyses when lidar estimates are compared with other wind speed observations, particularly for further range-gates as the distances between $A$ and $B$ becomes larger. The wind speeds varied between 1-8 $\mathrm{m} \mathrm{s}^{-1}$ during the data-collection period (30-min-mean dataset, KSS CSAT3 anemometer) which, when combined with the length-scales of beam separation, gives a timescale ( $\tau$ = distance $/$ speed) of 5-218 s. Since one would expect the velocity fields in both beams to be similar only at timescales $\gg \tau$, the 30 -min averaging period is adequate.

The Doppler resolution of $0.023 \mathrm{~m} \mathrm{~s}^{-1}$ means that when the wind is blowing parallel to a single beam, wind speeds above $0.023 \mathrm{~m} \mathrm{~s}^{-1}$ are required for detection, and this increases to infinity for the limit at perpendicular wind $(0.023 / \cos \alpha$, where $\alpha$ is the direction with respect to the beam). For the duo-beam configuration, one must consider the combined effect of the two beams: the worst case is only $0.12 \mathrm{~m} \mathrm{~s}^{-1}$ perpendicular to the mid-point between the two beams.

\section{Inter-comparison of wind measurements}

Compared to climatological means (1971-2000 SE England data for Feb-May, Met Office 2012), the study period was less cloudy (113\% sunshine hours), drier (49\% rainfall) and slightly warmer $\left(+1.5^{\circ} \mathrm{C}\right.$ mean temperature) than normal. The 30 -min-mean KSS air temperature ranged from -0.2 to $25.8^{\circ} \mathrm{C}$. There is broad agreement between the wind speeds measured by different instruments (Fig. 2). The net all-wave radiation increases through the period; strong diurnal cycles in both radiation and wind-speed are evident which is indicative of convection.

When comparing the 30-min-mean wind speeds, we might expect a difference in the wind speed over small spatial and temporal scales between measurements in an urban atmosphere (J.F. Barlow and Coceal, 2009; Roth, 2000). Wind-speed comparisons are made between some of the equipment (Table 1). First, the point measurements are compared to one another: a 3D anemometer (CSAT3) at KSK, and both a 3D (CSAT3) and 2D (WXT 510) sonic anemometer at KSS. The two instruments at the same site have a small mean bias error (row $b=-0.07 \mathrm{~m} \mathrm{~s}^{-1}$ ). The greater mean bias error for the two nearby sites (row a $=+0.44 \mathrm{~m} \mathrm{~s}^{-1}$ and $\mathrm{c}=-0.50 \mathrm{~m} \mathrm{~s}^{-1}$ ) is qualitatively consistent with their height difference. 
The smallest root-mean-square error ( $r m s e)$ is associated with equipment on the same mast (row $b=0.35 \mathrm{~m} \mathrm{~s}^{-1}$ ). This rmse increases for the sensors between the two sites (rows $\mathrm{a}=0.71 \mathrm{~m} \mathrm{~s}^{-1}$, $c=0.73 \mathrm{~m} \mathrm{~s}^{-1}$ ). Comparison of lidar range-gate 4 with KSK CSAT3 data gives rmse values of 0.65 , 0.67 , and $0.68 \mathrm{~m} \mathrm{~s}^{-1}$ (Table $1 \mathrm{~d}-\mathrm{f}$, Fig. 3), indicating that the random error in the lidar-derived winds is similar to that between standard point measurements with the same spatial separation.

The lidar mean bias error (mbe) was always positive (rows $d-h$ ), which is perhaps unsurprising given that the lidar beam is at slightly higher altitude than BLS and KSK sites (Fig. 1b), and that the average wind speed is dominated by range-gates above the river (rows $g-h$ ), since the airflow in those range-gates is faster than above land (see section 4.1).

Possible reasons for the larger rmse in the comparison between lidar and BLS (rows g- $h$ ) could be: (I) the lidar data cover only part of the BLS path, (II) the lidar operating method has a larger effective sampling volume (i.e. separated A \& B beams), (III) the lidar was not continuously operating in this custom mode (and thus a difference in temporal sampling between lidar and other measures can occur), (IV) the path heights are not identical (although this has a more-obvious impact on the mbe, it might also affect rmse given spatio-temporal variability in the urban atmosphere).

We can estimate the spread in wind-speed estimates about the true mean, due to the lidar temporal-sampling strategy, via standard sampling theory (Kaimal and Finnigan, 1994) under the assumption of independence in atmospheric turbulent wind measurements (never truly possible, though we often assume it). For the lidar, there are 36 samples in each 30 -min period. Hence, given $\sigma_{\mathrm{U}}$ from the KSK mast, the estimate of spread caused by temporal sampling is $\sigma_{\mathrm{U}} / N^{0.5}=0.3 \mathrm{~m} \mathrm{~s}^{-1}$. It is thus plausible that the relatively-coarse temporal sampling of the lidar is a contributor to the larger rmse between the lidar and the other methods (rows $d-h$ ) than between the sonic anemometers.

Overall, the results give confidence in the lidar sampling strategy and associated duo-beam trigonometric estimate of path of wind vectors. The airflow over the River Thames is now characterised using the lidar measurements.

\section{Airflow patterns over the river}

The KSS CSAT3 sonic anemometer is the highest of the anemometers and is thus regarded as the most representative measurement of airflow for the study area (because this instrument is assumed to be least affected by airflow features from specific buildings). Henceforth, only this point measurement is used for comparison with the lidar data. 
Wood et al. (2012) Science of the Total Environment DOI:10.1016/j.scitotenv.2012.10.061

\subsection{Transect of wind speed across river}

The transect of wind-speed magnitude using the lidar trigonometric method across the river was calculated for four different wind direction sectors (N, S, E, SW) defined from the KSS CSAT3 anemometer data (Fig. 4). For almost all range-gates and wind directions, the airflow estimated by the lidar is faster than the local-scale wind speed observed by the CSAT3 at KSS. For the north-bank gates ( 4 and 5 ), the lidar wind speed is less than the reference measurement for all wind sectors apart from southerly. Wind speed is greatest when the wind flows parallel to the river (E and SW).

Overall, lower relative wind speeds are found when the approach airflow is perpendicular to the river $(\mathrm{N}, \mathrm{S})$. Comparing different range-gates within the $\mathrm{N}$ or $\mathrm{S}$ cases, an acceleration is evident downstream of building-to-river roughness changes; this is consistent with a change in aerodynamic drag. This cross-river gradient is quite pronounced in the northerly airflow, with slower-thanreference winds for the first five range-gates, and a monotonically-increasing wind speed with distance for all lidar range-gates from the north to south. The southerly case is less clear. We conjecture that this is due to the curve in the river, or strong influence of particular buildings. However, a speed-up of airflow is still evident: again monotonically-increasing wind speed from south to north, but only after the first two range-gates.

At the two northern-most gates, the data show relatively high wind speed under southerly airflow conditions. This is despite the increase in surface roughness compared to the smooth river, when we would expect to see the beginning of a slowdown of the airflow. However, the height of roughness elements above mean river level exhibits a sudden increase at the north bank (Fig. 1). It is possible that the relatively high wind speed under southerly airflow conditions at those two northerly gates could be explained by vertical convergence of the streamlines affecting this measurement above the canopy layer.

\subsection{Channelling airflow along river}

Spatially, there is evidence of channelling airflow (Fig. 4): in these cases the wind is greatest over the centre of the river. This would be consistent with the difference in aerodynamic surface roughness, i.e. greater drag over the built areas than over the river. This effect is clearest for easterly airflow, where there is a long fetch of nearly-straight river. However, for the south-westerly cases, the lidar beams' geometry is perhaps more susceptible to the strong bend in the river (perhaps also the reason for the more complex airflows on the south bank for southerly cases, section 4.1). This will cause more variation in the three-dimensional airflow (such as any wind-direction turning effects) which is apparent in the lidar wind speed profile for the SW sector (Fig. 4). Winds coming from this direction are generally stronger than those coming from the south, however the 
channelling effect is far less pronounced than for the easterly sector and the location of peak wind speed is displaced to the south of the centre of the river.

There is further evidence for channelling if one compares the wind direction over the river with that of the reference anemometer (Fig. 5). The deviations from the 1:1 line are similar to that observed of rectified channelling in street-canyon studies (Barlow et al., 2009). For example, given a large spread in background winds between 60 and $120^{\circ}$, the airflow over the centre of the river varies over a smaller range (only $70-90^{\circ}$ ). Also evident is the channelling in the synoptic prevailing wind direction from the south west: when the background airflow ranges between 170 and $230^{\circ}$, wind directions over the river centre are diverted towards the west. There was low data availability for airflow from the south-east, due to the frequency of synoptic-scale airflow directions during the field campaign.

\subsection{Turbulence intensity}

For applications of ventilation and thus air quality, we also wish to understand the turbulent nature of the airflow. The current lidar configuration allows a simple analysis (detailed analysis for turbulent structures could be obtained with different scanning strategies, (Pichugina et al., 2008)). In cases where the wind flows parallel to the lidar beams $A$ and $B$ (within $\pm 15^{\circ}$ ), streamwise turbulence intensity was defined (without using the duo-beam method) by using along-beam 30-min mean radial wind speed to define turbulence intensity in each beam as $I_{\mathrm{U}}=\sigma_{\mathrm{U}} / U$ (Fig. 6). There is clear evidence that the air becomes less turbulent as it flows from built-environment to above the river, for both southerly and northerly airflow. It is noteworthy how clear the relationship is despite complexity in the study area since one assumes that the airflow is highly variable in space and time, given the slight change in ground height and variety in building heights (Fig. 1a).

Indeed, average turbulence intensity from the anemometers $\left(I_{\mathrm{U}}^{\mathrm{KSS}}=0.37\right.$ and $I_{\mathrm{U}}^{\mathrm{KSK}}=0.44$; not shown) for the study period are comparable to the lidar. The average study-period turbulence intensity for lidar range-gate 4 (mean of both beams) was $I_{\mathrm{U}}^{\text {lidar }}=0.34$. It is not surprising that $I_{\mathrm{U}}^{\text {lidar }}$ is less than the sonic anemometers, given that the lidar has a greater spatial ( $30 \mathrm{~m})$, temporal ( $3.5 \mathrm{~s})$ and numerical $\left(0.023 \mathrm{~m} \mathrm{~s}^{-1}\right)$ resolution. At the normalized height of the lidar range-gate- 4 (also approximately KSK) to mean building height, Roth (2000) suggests a value of $I_{\mathrm{U}}=0.37$; the turbulence values for KSK and lidar are either side of this.

\subsection{Diurnal cycle}

The study period had many clear days. The sunniest days were defined where at least five daytime hours had $>200 \mathrm{~W} \mathrm{~m}^{-2}$ downwelling shortwave radiation, and none of the 30-min averages 
in the central four hours of the day were $<150 \mathrm{~W} \mathrm{~m}^{-2}$ : this yielded a sample of 46 days of strongest sunshine. The cloudiest days were defined as days where at least five of the daylight hours of the day had $<200 \mathrm{~W} \mathrm{~m}^{-2}$ downwelling shortwave radiation, and none of the 30-min-mean data in the day were $>300 \mathrm{~W} \mathrm{~m}^{-2}$ : this yielded a sample of 15 days with the least sunshine. The sunny days have a clear diurnal cycle of wind speed (Fig. 7). This is consistent with the canonical clear-sky diurnal variation of near-surface wind speed caused by stability changes: increased vertical exchange of momentum by day and reduced by night. We find that sunny days had a greater diurnal cycle than cloudy conditions, where the diurnal effect is not evident (given the confidence intervals, Fig. 7). The implication from this may be that airflow over the river is responding primarily to the convection developing over the surrounding urban area as a whole, rather than the local energy balance of the river, where the sensible heat flux is likely to be lower. This is in accordance with source area considerations-observations at these measurement heights above the ground are influenced by a local scale surface upwind of the measurement locations and not only by surface characteristics in the immediate vicinity.

\section{Conclusions}

In this study, airflow over the River Thames was analyzed using a technique developed and tested using a scanning Doppler lidar to estimate a horizontally resolved path of wind vectors. This was tested against both sonic anemometry and cross-beam winds from a scintillometer. This duobeam lidar method proved successful in giving accurate measurements of wind speed; with point comparisons giving similar rmse to that between standard anemometry, as also reported by others (Friedrich et al., 2012).

Novel scanning lidar techniques such as the one presented here and elsewhere (Collier et al., 2005; Pichugina et al., 2008) allow observations of the airflow in complex environments such as roughness sub-layers, internal boundary layers, or for flux-footprint estimates. However, care should be taken, because the duo-beam technique naturally has separating beams with distance-this could be problematic for some very complex airflows where we expect large temporal and spatial differences in wind, such as lower in the roughness sub-layer (Wood et al., 2009). Perhaps repeating the technique at other locations and comparison with models (e.g. wind tunnel, LES, DNS) could help the further exploitation of lidar for such analyses.

The new lidar operating method gave a horizontally-resolved paths of wind vectors above the River Thames, which revealed: (i) channelling airflow along the river; (ii) mean and turbulent wind adjustment as expected for roughness change to/from river/built surfaces; (iii) the diurnal variation in winds above the river which was indicative of the airflow above the river being strongly coupled to convection triggered over the built-up surroundings. 
The present paper increases understanding of ventilation within central London around the River Thames. Particularly, there are important consequences for dispersion of emissions along the river. For example, there are many busy roads on London's riverbanks, such as 'Embankment' which is located on the northern bank of the River Thames in our study area and beyond (emissions from Embankment are shown clearly on London's air quality maps, London Air Quality Network, 2005).

\section{Acknowledgements}

Funding came from EPSRC EP/G029938/1, EUFP7 MegaPoli (212520), EUFP7 Bridge (211345), UK Met Office, NERC NE/H00324X/1. Ewan O'Connor and Guy Pearson advised on implementing lidar SNR quality control. In the ACTUAL project (www.actual.ac.uk), Marc Stringer and Gary Robinson provided data support; Rosy Wilson and John Lally provided technical support. Virtual London DEM is used courtesy of Greater London Authority. Thanks to all at KCL who contributed to the data collection; KCL Directorate of Estates \& Facilities for giving us the opportunity to operate the various measurement sites; funding support from KCL. Annika Nordbo and Karoliina Pilli-Sihvola commented on the manuscript.

\section{Tables:}

Table 1. Comparisons of wind speeds (30-min-mean dataset, number of samples $\mathrm{N}$ ) between different methods of wind speed measurement (CSAT3 $=3 \mathrm{D}$ sonic anemometer, Lidar, BLS = scintillometer, WXT510 = 2D sonic anemometer), expressed by the Spearman's rank correlation coefficient $\left(r_{s}\right)$, root-mean-square error ( $\left.r m s e\right)$ and mean bias error (mbe). Rows $d$ and e are the lidar wind from range-gate $4(90-120 \mathrm{~m})$, which is compared with the equivalent coordinate-rotated component in the anemometer data from KSK. Row $f$ is the duo-beam estimate of wind speed magnitude at lidar rangegate 4. Spatially-resolved lidar data from the duo-beam method were averaged according to the weighting function of the BLS and the calculated wind was the coordinate-rotated component perpendicular to the BLS (rows g-h): in row $\mathrm{g}$ all wind sectors are used (excluding that from 10-120\%), whilst row $\mathrm{h}$ has only positive BLS winds (see section 2.3).

\begin{tabular}{lllllll}
\hline & Measurement (i) & Measurement (ii) & $r_{\mathrm{s}}$ & $\begin{array}{l}\text { rmse } \\
\left(\mathrm{m} \mathrm{s}^{-1}\right)\end{array}$ & $\begin{array}{l}\mathrm{mbe}, \mathrm{i}-\mathrm{ii} \\
\left(\mathrm{m} \mathrm{s}^{-1}\right)\end{array}$ & $\mathrm{N}$ \\
\cline { 2 - 7 } $\mathrm{a}$ & KSS CSAT3 & KSK CSAT3 & 0.79 & 0.71 & 0.44 & 3963 \\
$\mathrm{~b}$ & KSS CSAT3 & KSS WXT510 & 0.78 & 0.35 & -0.07 & 3913 \\
$\mathrm{c}$ & KSK CSAT3 & KSS WXT510 & 0.85 & 0.73 & -0.50 & 4061 \\
$\mathrm{~d}$ & Lidar gate-4 beam-A & KSK CSAT3 & 0.82 & 0.68 & 0.43 & 3915 \\
$\mathrm{e}$ & Lidar gate-4 beam-B & KSK CSAT3 & 0.79 & 0.67 & 0.52 & 3927 \\
$\mathrm{f}$ & Lidar gate-4, duo-beam & KSK CSAT3 & 0.85 & 0.65 & 0.34 & 3915 \\
$\mathrm{~g}$ & Lidar weighted & BLS & 0.48 & 1.63 & 0.95 & 2279 \\
$\mathrm{~h}$ & Lidar weighted $u(+\mathrm{ve})$ & BLS $u(+\mathrm{ve})$ & 0.87 & 1.12 & 0.48 & 1737 \\
$\mathrm{i}$ & KSK CSAT3 & BLS & 0.30 & 2.13 & 0.02 & 2219 \\
\hline
\end{tabular}




\section{Figures:}
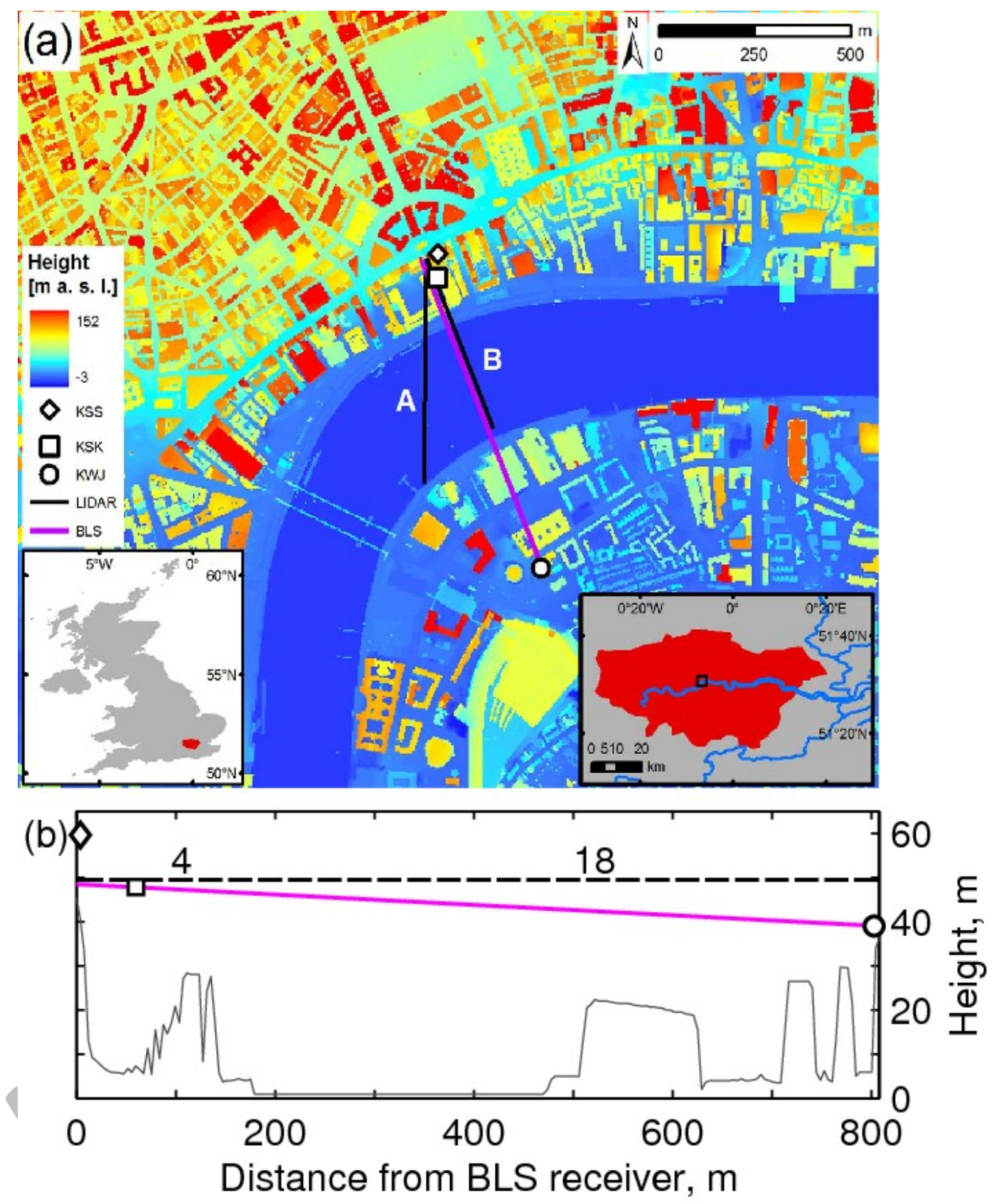

Fig. 1. (a) Heights of buildings, river and ground above mean river level in study area ( $4 \mathrm{~m}$ resolution) with site locations and measurement paths of BLS and lidar, beam $A\left(180^{\circ}\right)$ and $B\left(157.8^{\circ}\right)$, respectively. Lidar beam A crosses the river banks at 180 and $515 \mathrm{~m}$, beam B at 170 and $470 \mathrm{~m}$. The location within Greater London is shown (right inset) and within the United Kingdom (left inset). Mean river-flow direction is towards the east. (b) An x-z slice along the BLS beam (i.e. roughly North-South) between Strand and KWJ (the beam slant is $0.7^{\circ}$ ). The surface (thin grey line) is buildings, ground or river. The location of lidar range-gates are shown, 4 and 18 are labelled. [This figure is available in colour online] 


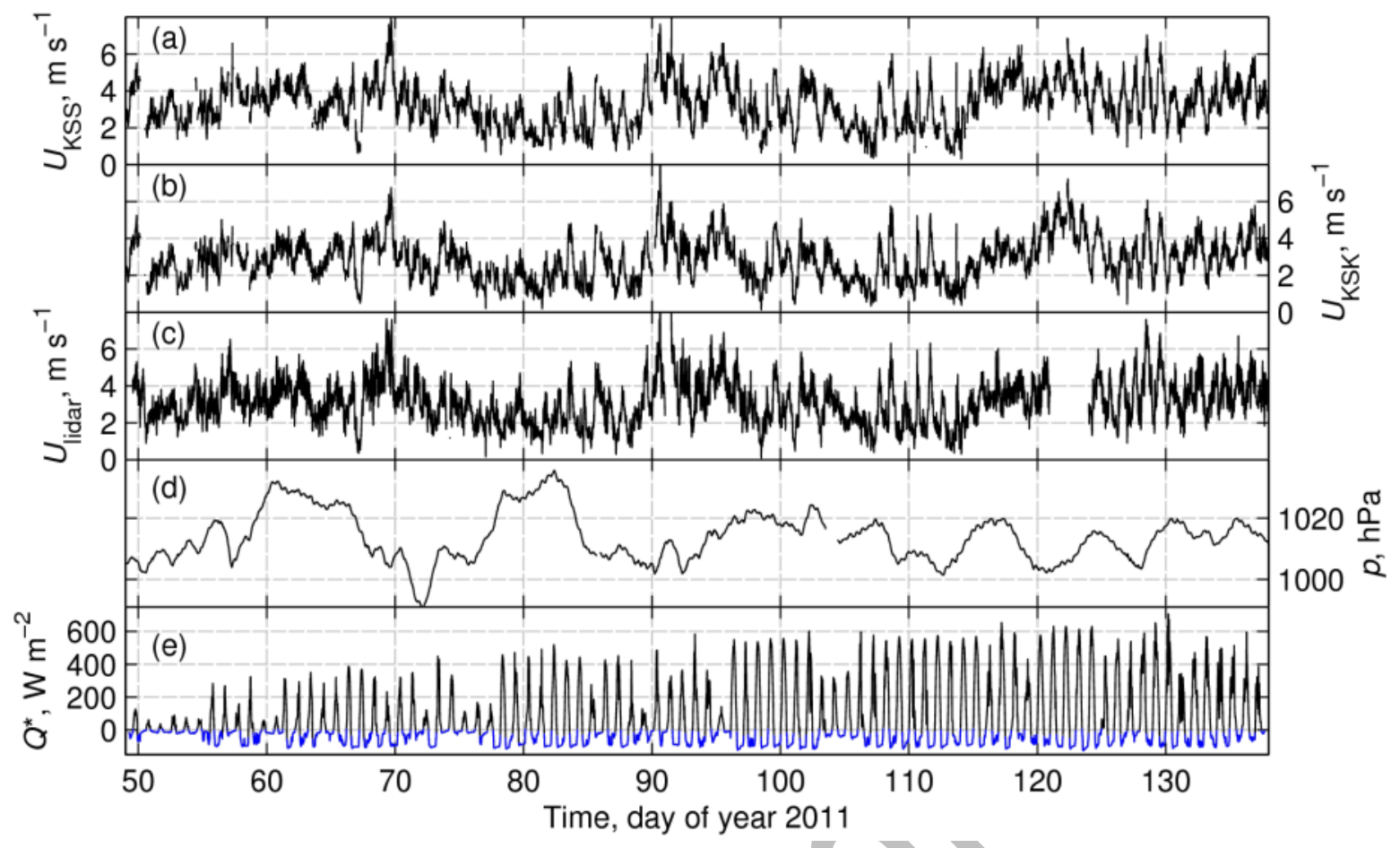

Fig. 2. Conditions (30-min-mean dataset) during the study period. Wind speeds from (a) KSS CSAT3, (b) KSK CSAT3, (c) lidar gate 4 from duo-beam method. Station atmospheric pressure (d) and net all-wave radiation (e) at KSS.

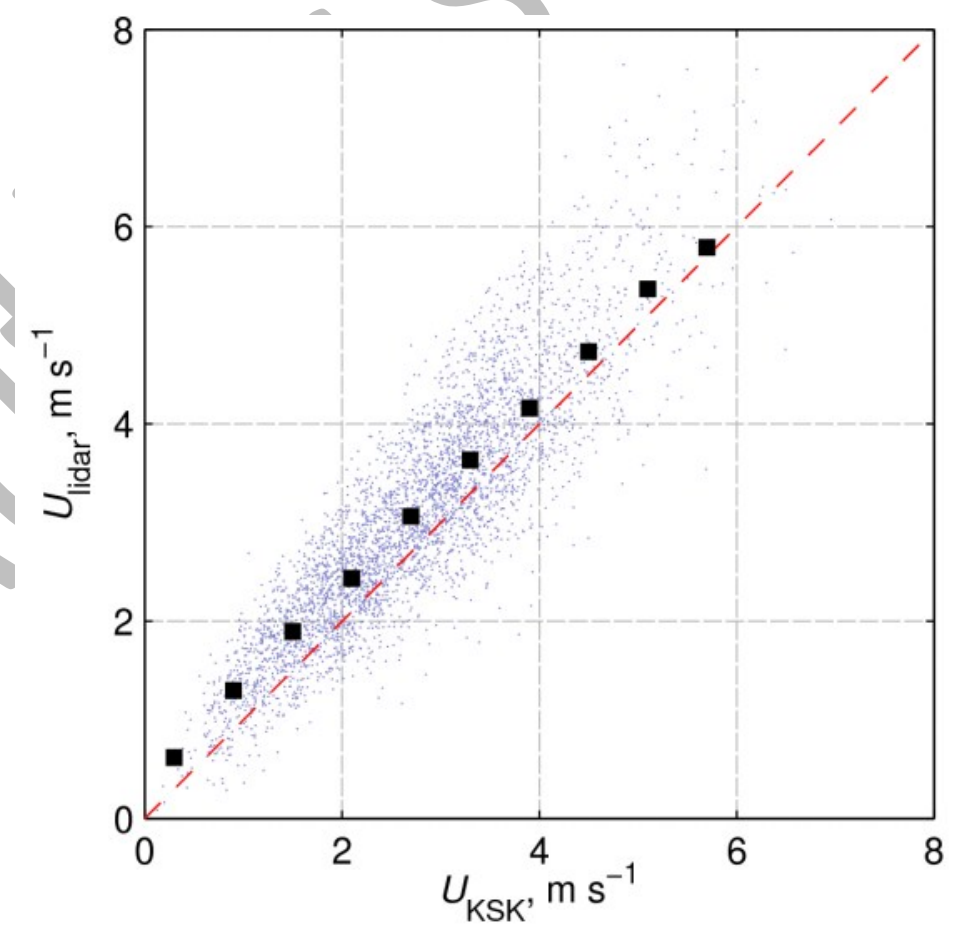

Fig. 3. Lidar wind speed magnitude $\left(U_{\text {lidar }}\right)$ against KSK CSAT3 wind speeds $\left(U_{K S K}\right)$ from the duo-beam method; 30-min-mean dataset (grey crosses). The data are those in row ' $\mathrm{f}$ ' in Table 1. Average wind directions are black squares $\left(0.5 \mathrm{~m} \mathrm{~s}^{-1}\right.$ bins from KSS). The 1:1 line is shown. 


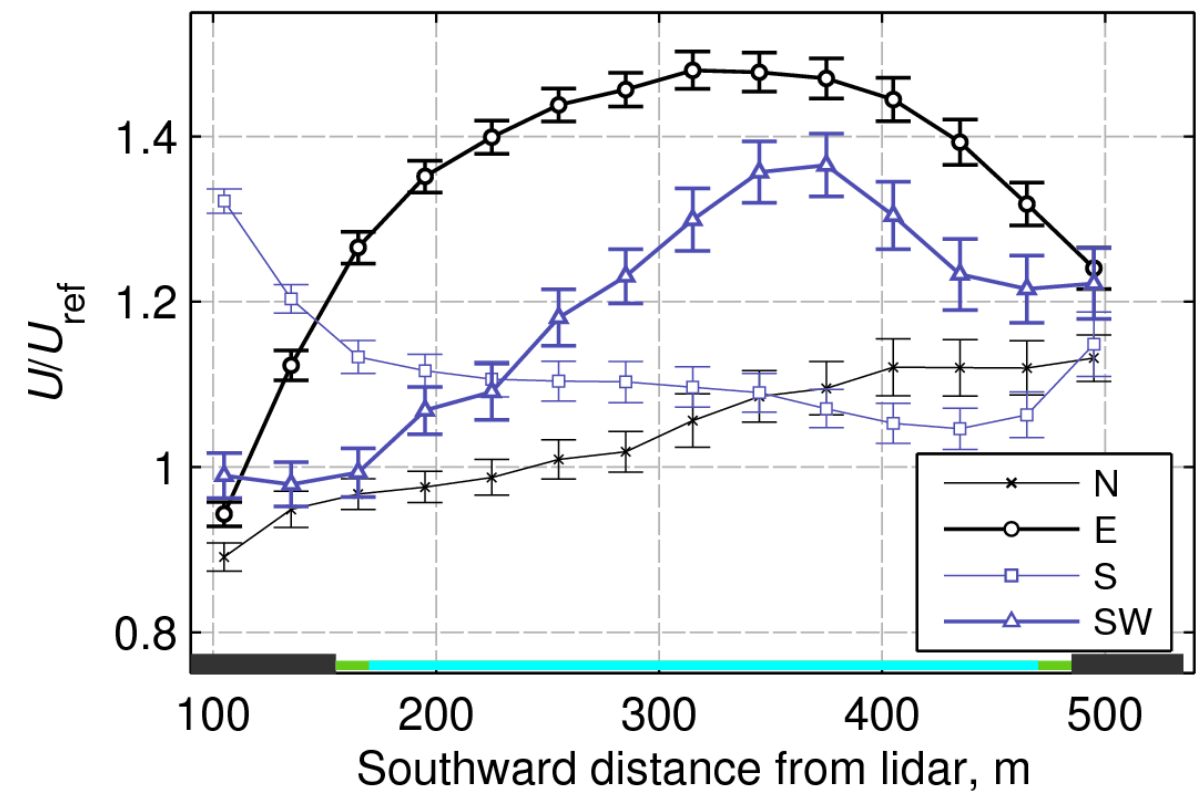

Fig. 4. Mean wind speed transect over the River Thames (from the lidar, i.e. North to South). Wind sectors are defined as bearings using KSS CSAT3 30-min-mean dataset. Perpendicular to the river: northerly (N 320-350 ), southerly (S $150-170^{\circ}$ ); and along the river: easterly $(E$ 85-95 $)$, south-westerly (SW 250-290 ${ }^{\circ}$. Wind speeds from the lidar duo-beam method (U) are normalized by a reference wind speed $\left(U_{\text {ref }}\right)$ : the wind speed of KSS CSAT3. The river bank is indicated by shading above the $x$-axis (dark grey: built, green: bankside, light blue: river). Bars show the $95 \%$ confidence intervals about the mean in each range-gate distance.

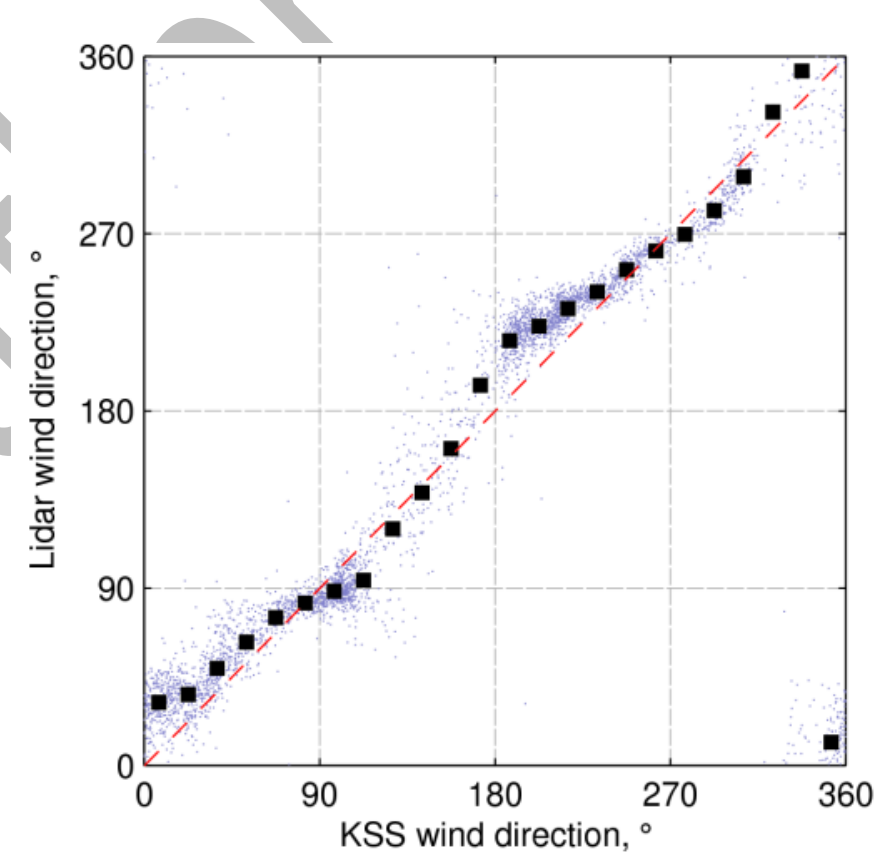

Fig. 5. Wind direction $\left(^{\circ}\right.$ ) above the centre of river (lidar duo-beam method at range-gate 12) and KSS CSAT3 anemometer; 30-min-mean dataset (grey crosses). Average wind directions are black squares (10 bins from KSS). 1:1 line shown. 


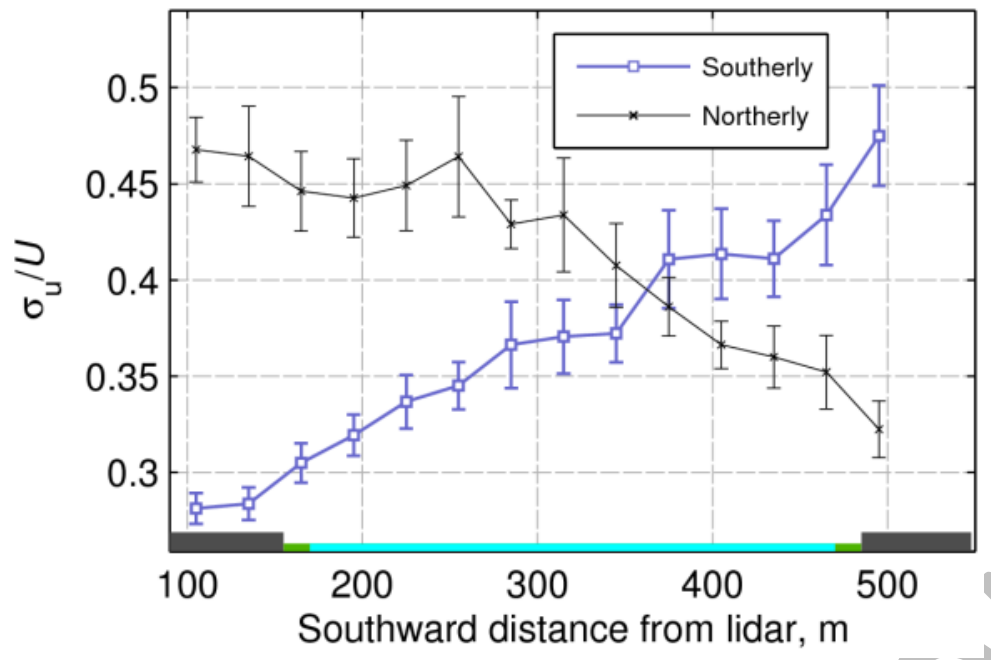

Fig. 6. Turbulence intensity transects when the airflow is across the river $\left(\sigma_{u}\right.$ and $U$ both defined locally, i.e. within each range-gate in individual beams). The subset of cases is where wind direction (KSS CSAT3) is within $\pm 15^{\circ}$ of beams A and $B$. The river bank is indicated by shading above the x-axis (dark grey: built, green: bankside, light blue: river). Bars show the $95 \%$ confidence intervals.

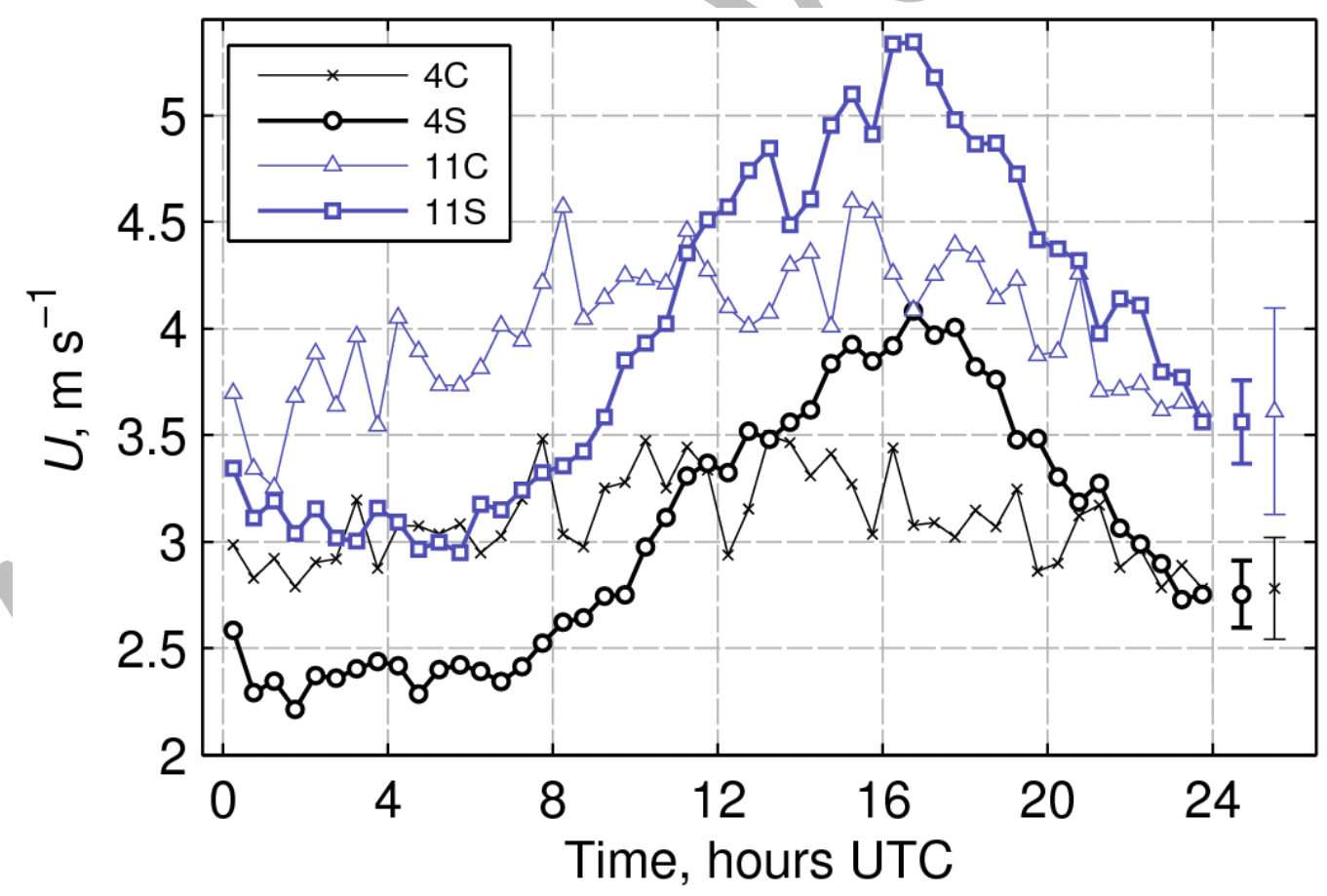

Fig. 7. Diurnal variation of wind speed in two lidar range-gates ( 4 near north bank, 11 centre of river) for sunny (S) and cloudy (C) days. For clarity, only a typical confidence interval (95\%) shown for each range-gate (right of plot). The KSS CNR1 radiometer was used to define sunny/cloudy days. 


\section{References}

Balogun AA, Tomlin AS, Wood CR, Barlow JF, Belcher SE, Smalley RJ, et al. In-street wind direction variability in the vicinity of a busy intersection in central London. Bound-Layer Meteorol 2010;136:489-513.

Barlow JF, Coceal O. A review of urban roughness sublayer turbulence, Met Office Technical Report 527, Exeter 2009.

Barlow JF, Dunbar TM, Nemitz EG, Wood CR, Gallagher MW, Davies F, et al. Boundary layer dynamics over London, UK, as observed using Doppler lidar during REPARTEE-II. Atmos Chem Phys 2011;11:2111-25.

Barlow JF, Dobre A, Smalley RJ, Arnold SJ, Tomlin AS, Belcher SE. Referencing of street-level flows measured during the DAPPLE 2004 campaign. Atmos Environ 2009;43:5536-44.

Best MJ. Representing urban areas within operational numerical weather prediction models. BoundLayer Meteorol 2005;114:91-109.

Ching JKS. Urban-scale variations of turbulence parameters and fluxes. Bound-Layer Meteorol 1985;33:335-61.

Cho M-R. The politics of urban nature restoration: The case of Cheonggyecheon restoration in Seoul, Korea. Int Develop Plan Rev 2010;32:145-65.

Chou CC-K, Lee C-T, Chen W-N, Chang S-Y, Chen T-K, Lin C-Y, et al. Lidar observations of the diurnal variations in the depth of urban mixing layer: a case study on the air quality deterioration in Taipei, Taiwan. Sci Tot Environ 2007;374:156-66.

Collier CG, Davies Fay, Bozier KE, Holt AR, Middleton DR, Pearson GN, et al. Dual-Doppler Lidar Measurements for Improving Dispersion Models. Bull Amer Meteorol Soc 2005;86:825-38.

Ding A, Wang Tao, Zhao M, Wang Tijian, Li Z. Simulation of sea-land breezes and a discussion of their implications on the transport of air pollution during a multi-day ozone episode in the Pearl River Delta of China. Atmos Environ 2004;38:6737-50.

van Dinther D, Hartogensis OK, Moene AF. Crosswind from a Single Aperture Scintillometer using Spectral Techniques. J Atmos Ocean Tech 2012. DOI: 10.1175/JTECH-D-12-00069.1.

Eliasson I, Offerle B, Grimmond CSB, Lindqvist S. Wind fields and turbulence statistics in an urban street canyon. Atmos Environ 2006;40:1-16.

Evans S. 3D cities and numerical weather prediction models: An overview of the methods used in the LUCID project. 148. CASA working document, University College London 2009;44:0-18.

Fortuniak K, Pawlak W. Turbulence characteristics and energy balance on urbanized area - Łódź case study. EMS Annual Meeting Abstracts. 2011. p. 785. 
Friedrich K, Lundquist JK, Aitken M, Kalina EA, Marshall RF. Stability and turbulence in the atmospheric boundary layer: A comparison of remote sensing and tower observations. Geophys Res Lett 2012;39:1-6.

Kaimal JC, Finnigan JJ. Atmospheric boundary layer flows, their structure and measurements. Oxford University Press: New York, USA; 1994.

Kanda M, Moriwaki R, Roth M, Oke T. Area-averaged sensible heat flux and a new method to determine zero-plane displacement length over an urban surface using scintillometry. BoundLayer Meteorol 2002;105:177-93.

Kastner-Klein P, Fedorovich E, Rotach MW. A wind tunnel study of organised and turbulent air motions in urban street canyons. J Wind Eng Indust Aerodyn 2001;89:849-61.

Kotthaus S, Grimmond CSB. Identification of micro-scale anthropogenic CO2, heat and moisture sources - processing eddy covariance fluxes for a dense urban environment. Atmos Environ 2012;57:301-16.

Lagouarde J-P, Irvine M, Bonnefond J-M, Grimmond CSB, Long N, Oke TR, et al. Monitoring the Sensible Heat Flux over Urban Areas using Large Aperture Scintillometry: Case Study of Marseille City During the Escompte Experiment. Bound-Layer Meteorol 2006;118:449-76.

Lindberg F, Grimmond CSB. Nature of vegetation and building morphology characteristics across a city: influence on shadow patterns and mean radiant temperatures in London. Urb Ecosys 2011;14:617-34.

London Air Quality Network. AirQuality in London 2003, Environmental Research Group, King's College London, G. Fuller (Ed.), Report No. 11. 2005.

MacDonald RW, Griffiths RF, Hall DJ. An improved method for the estimation of surface roughness of obstacle arrays. Atmos Environ 1998;32:1587-864.

Mestayer PG, Rosant J-M, Rodriguez F, Rouaud J-M. The experimental campaign FluxSAP 2010: Climatological measurements over a heterogeneous urban area. Inter Assoc Urb Clim News 2011;40:25-33.

Met Office. www.metoffice.gov.uk/climate/uk, date accessed 15 May 2012.

Orton PM, McGillis WR, Zappa CJ. Sea breeze forcing of estuary turbulence and air-water CO 2 exchange. Geophys Res Lett 2010;37.

O'Connor EJ, Illingworth AJ, Brooks IM, Westbrook CD, Hogan RJ, Davies F, et al. A Method for Estimating the Turbulent Kinetic Energy Dissipation Rate from a Vertically Pointing Doppler Lidar, and Independent Evaluation from Balloon-Borne In Situ Measurements. J Atmos Ocean Tech 2010;27:1652-64.

Pichugina YL, Tucker SC, Banta RM, Brewer WA, Kelley ND, Jonkman BJ, et al. Horizontal-Velocity and Variance Measurements in the Stable Boundary Layer Using Doppler Lidar: Sensitivity to Averaging Procedures. J Atmos Ocean Tech 2008;25:1307-27. 
Poggio LP, Furger M, Prévôt AH, Graber WK, Andreas EL. Scintillometer Wind Measurements over Complex Terrain. J Atmos Ocean Tech 2000;17:17-26.

Port of London. Handbook of Tide Tables and Port Information. Gravesend, UK; 2011.

Roth M. Review of atmospheric turbulence over cities. Quart J Roy Meteorol Soc 2000;126:941-90.

Roth M, Salmond JA, Satyanarayana ANV. Methodological considerations regarding the measurement of turbulent fluxes in the urban roughness sublayer: The role of scintillometery. Bound-Layer Meteorol 2006;121:351-75.

Salizzoni P, Soulhac L, Mejean P. Street canyon ventilation and atmospheric turbulence. Atmos Environ 2009;43:5056-67.

Scintec. Scintec Boundary Layer Scintillometer Hardware Manual. Version 2.07. Rottenburg, Germany. 2011.

Spronken-Smith RA, Oke TR, Lowry WP. Advection and the surface energy balance across an irrigated urban park. Int J Climatol 2000;20:1033-47.

Vardoulakis S, Dimitrova R, Richards K, Hamlyn D, Camilleri G, Weeks M, et al. Numerical Model Inter-comparison for Wind Flow and Turbulence Around Single-Block Buildings. Environ Model Assess 2011;16:169-81.

Wang Ting-i, Ochs GR, Lawrence RS. Wind measurements by the temporal cross-correlation of the optical scintillations. Appl Opt 1981;20:4073-81.

Ward HC, Evans JG, Grimmond CSB. Effects of Non-Uniform Crosswind Fields on Scintillometry Measurements. Bound-Layer Meteorol 2011;141:143-63.

Wood CR, Gierens R, Kouznetsov RD, Nordbo A, Järvi L, Kukkonen J. The structure parameter for temperature over Helsinki from sonic anemometry and scintillometry. J Atmos Ocean Tech 2012;Submitted.

Wood CR, Barlow JF, Belcher SE, Dobre A, Arnold SJ, Balogun AA, et al. Dispersion Experiments in central London: The 2007 DAPPLE project. Bull Amer Meteorol Soc 2009;90:955-69.

Yuan C, Ng E. Building porosity for better urban ventilation in high-density cities - A computational parametric study. Build Environ 2012;50:176-89. 